\title{
The Prognostic Value of ctDNA and bTMB on Immune Checkpoint Inhibitors in Human Cancer
}

\author{
Jiayan Wei ${ }^{\dagger}$, Jia Feng ${ }^{\dagger}$, Yiming Weng, Zexi Xu, Yao Jin, Peiwei Wang, Xue Cui, \\ Peng Ruan, Ruijun Luo, $\mathrm{Na} \mathrm{Li}^{*}$ and Min Peng ${ }^{*}$
}

Department of Oncology, Renmin Hospital of Wuhan University, Wuhan, China

OPEN ACCESS

Edited by:

Roberta Zappasodi, Memorial Sloan Kettering Cancer

Center, United States

Reviewed by:

Yasin Senbabaoglu,

Genentech, Inc., United States

David Stephen Guttery,

University of Leicester,

United Kingdom

*Correspondence:

$\mathrm{Na} \mathrm{Li}$

nalirenmin@163.com

Min Peng

mpeng320@whu.edu.cn

${ }^{t}$ These authors share first authorship

Specialty section:

This article was submitted to

Cancer Immunity

and Immunotherapy,

a section of the journa

Frontiers in Oncology

Received: 08 May 2021 Accepted: 13 September 2021 Published: 01 October 2021

Citation:

Wei J, Feng J, Weng $Y, X u Z$, Jin $Y$, Wang $P$, Cui $X$, Ruan $P$, Luo R, Li N and Peng M (2021)

The Prognostic Value of ctDNA and

bTMB on Immune Checkpoint

Inhibitors in Human Cancer.

Front. Oncol. 11:706910.

doi: 10.3389/fonc.2021.706910
Background: Circulating tumor DNA (ctDNA) levels and blood tumor mutation burden (bTMB) have a significant impact on the prognosis of tumor patients. However, their prognostic role in immune checkpoint inhibitors (ICls) in cancer patients is still unclear.

Methods: We used the Review Manager software (version 5.3) to perform a metaanalysis based on the published literature to explore the prognostic value of ctDNA and bTMB in patients receiving immunotherapy. We extracted the hazard ratios (HRs) of progression-free survival (PFS) and overall survival (OS) for each included study and their respective 95\% confidence intervals (Cls) and p-values for analysis.

Results: Thirteen studies were included in the meta-analysis. Higher ctDNA levels were significantly associated with shorter OS $(\mathrm{HR}=3.35,95 \% \mathrm{Cl}=2.49-4.51, p<0.00001)$ and PFS $(\mathrm{HR}=3.28,95 \% \mathrm{Cl}=2.47-4.35, p<0.00001)$. The results of ctDNA subgroup analysis showed that high posttreatment ctDNA levels significantly correlated with shorter OS in cancer patients receiving $\mathrm{ICls}(\mathrm{HR}=5.09,95 \% \mathrm{Cl}=1.43-18.07, p=0.01)$. Moreover, patients with ctDNA clearance had better OS $(\mathrm{HR}=4.94,95 \% \mathrm{Cl}=2.96-$ 8.26, $p<0.00001)$. Patients with high posttreatment ctDNA levels had shorter PFS (HR = $3.00,95 \% \mathrm{Cl}=2.02-4.46, p<0.00001$ ) and those with ctDNA clearance had longer PFS $(\mathrm{HR}=4.61,95 \% \mathrm{Cl}=2.78-7.65, p<0.00001)$. However, there was no statistically significant difference in the OS benefits between a high and a low bTMB after $\mathrm{ICl}$ therapy $(\mathrm{HR}=0.68,95 \% \mathrm{Cl}=0.33-1.37, p=0.28)$.

Conclusions: The host immune system and tumor burden together determine whether cancer patients can benefit from $\mathrm{ICl}$ therapy. Our systematic review and meta-analysis revealed for the first time that the levels of pretreatment and posttreatment ctDNA and the clearance of ctDNA can independently be used as prognostic factors for antitumor immunotherapy, while bTMB cannot. In conclusion, ctDNA levels have great potential as an assistant tool for radiological assessments to make clinical therapeutic decisions. The prognostic utility of bTMB still requires further exploration.

Keywords: ctDNA, bTMB, immune checkpoint inhibitor, prognosis, biomarker, meta-analysis 


\section{INTRODUCTION}

Circulating tumor DNA (ctDNA), a component of cell-free DNA ( $\mathrm{cfDNA}$ ), is released from apoptotic or necrotic tumor cells (1). ctDNA can be measured by polymerase chain reaction (PCR) and next-generation sequencing (NGS) technology, and it is expected to be a new indicator for evaluating tumor burden and treatment response (2). Blood-based tumor mutation burden (bTMB) is the number of mutations per megabase (Mut/Mb) detected in the ctDNA sequencing region and is considered to be a neoantigen load marker that stimulates the immune response of $\mathrm{T}$ cells (3). In the past few decades, immune checkpoint inhibitors (ICIs) have been widely used and have shown remarkable effects in a variety of solid tumors, such as nonsmall cell lung cancer, melanoma, and renal cell carcinoma $(4,5)$. However, the objective response rate (ORR) was lower than 30\% in unselected patients (6), highlighting the need for new biomarkers to identify patients who are more likely to benefit from ICI therapy. Tissue TMB (tTMB) has been used in multiple studies as a biomarker to predict the response to immunotherapy. However, owing to its invasiveness and organizational spatial heterogeneity, operable, easily accessible, and real-time ctDNA and BTMB have attracted more attention.

Several studies have focused on the prognostic impact of ctDNA and bTMB in patients receiving immunotherapy (7-9). However, most of them are characterized by small sample sizes and low universality. Therefore, we conducted a systematic review and meta-analysis on this topic.

\section{MATERIALS AND METHODS}

\section{Search Strategy and Study Selection}

Relevant published literature was searched for using MEDLINE (PubMed) and EMBASE. The following search terms were used: ctDNA OR circulating biomarker AND immune checkpoint AND cancer NOT review, ctDNA AND predictive AND cancer AND immunotherapy. The last search was updated on August 28, 2021.

The included studies met the following criteria: 1) cohort studies or clinical trials that use ICIs for treatment and ctDNA or bTMB to predict efficacy; 2) the prognostic value of ctDNA or bTMB in cancer patients who had received immunotherapy was investigated; 3) hazard ratios (HRs) of overall survival (OS) and progression-free survival (PFS), as well as their $95 \%$ CIs and $p$ values, or sufficient data to calculate them.

The exclusion criteria were as follows: 1) reviews, case reports, meeting abstracts, letters, expert opinions, and animal studies; and 2) no English translation of the study.

\section{Data Extraction}

Data were extracted from the included studies. The following pieces of information were extracted from each study: author name, year of publication, tumor type, study type, blood biomarker type, timing of biomarker, biomarker detection method, cutoff point of blood biomarker, type of ICI used, type of outcome, and results (HRs and 95\% CIs).

\section{Quality Assessment}

The risk bias evaluation tool (Cochrane Handbook for Systematic Reviews of Interventions) was used to evaluate the quality of the included studies. Seven evaluation items were used to examine the quality of the research: random sequence generation, allocation concealment, blinding of participants and personnel, blinding of outcome assessment, incomplete outcome data, selective reporting, and other sources of bias.

\section{Statistical Analysis}

We used the Review Manager software (version 5.3) to analyze the prognostic effects of ctDNA and bTMB in tumor patients receiving ICI therapy. The HRs of PFS and OS and their 95\% CIs were used to calculate the pooled estimates of the meta-analysis. Statistical significance was set at $p<0.05$. The heterogeneity of each study was tested using the Higgins $I^{2}$ statistic. If $I^{2}$ was greater than $50 \%$, it was considered that there was significant heterogeneity between the studies, so the random effects model was used; otherwise, when there was no significant heterogeneity $\left(I^{2}<50 \%\right)$, the fixed effects model was selected. There is no absolute definition of ctDNA or bTMB. The cutoff points for ctDNA and bTMB are not uniform because the studies we included used different techniques to detect biomarkers. To better analyze the data, we defined those biomarkers with values greater than the cutoff points and were detectable, positive, and unclear as high levels of ctDNA or bTMB and, conversely, as low levels of ctDNA or bTMB.

\section{RESULTS}

\section{Study Characteristics}

A total of 484 articles were retrieved through a database search. Using the exclusion criteria listed above, we removed 4 duplicate articles, 305 articles not related to ctDNA and bTMB, and 162 articles from non-clinical studies. Thirteen articles were finally included in our meta-analysis. The enrollment process of this study is shown in Figure 1. Among the 13 included studies, regarding tumor types, four studies were on non-small cell lung cancer (NSCLC), four were on melanoma, one was on colorectal cancer, one was on biliary tract cancer, and one was on urothelial carcinoma; the remaining two were studies on a mixture of different cancers. Table 1 summarizes the characteristics of the 13 included studies.

\section{Risk of Bias}

Twelve of the 13 included studies were prospective cohort studies and only one was a retrospective cohort study, so the overall risk of bias was relatively low. Figures 2A, B summarize the risk bias of all the included studies. Figures 3A, B display the funnel plots showing no significant publication bias affecting the HRs of OS and PFS on ctDNA.

\section{Outcomes of Included Studies \\ Relationship Between ctDNA Levels and Response to Immunotherapy}

Overall, there were 10 studies on the prognostic value of ctDNA levels in the OS of patients receiving immunotherapy. Elevated 


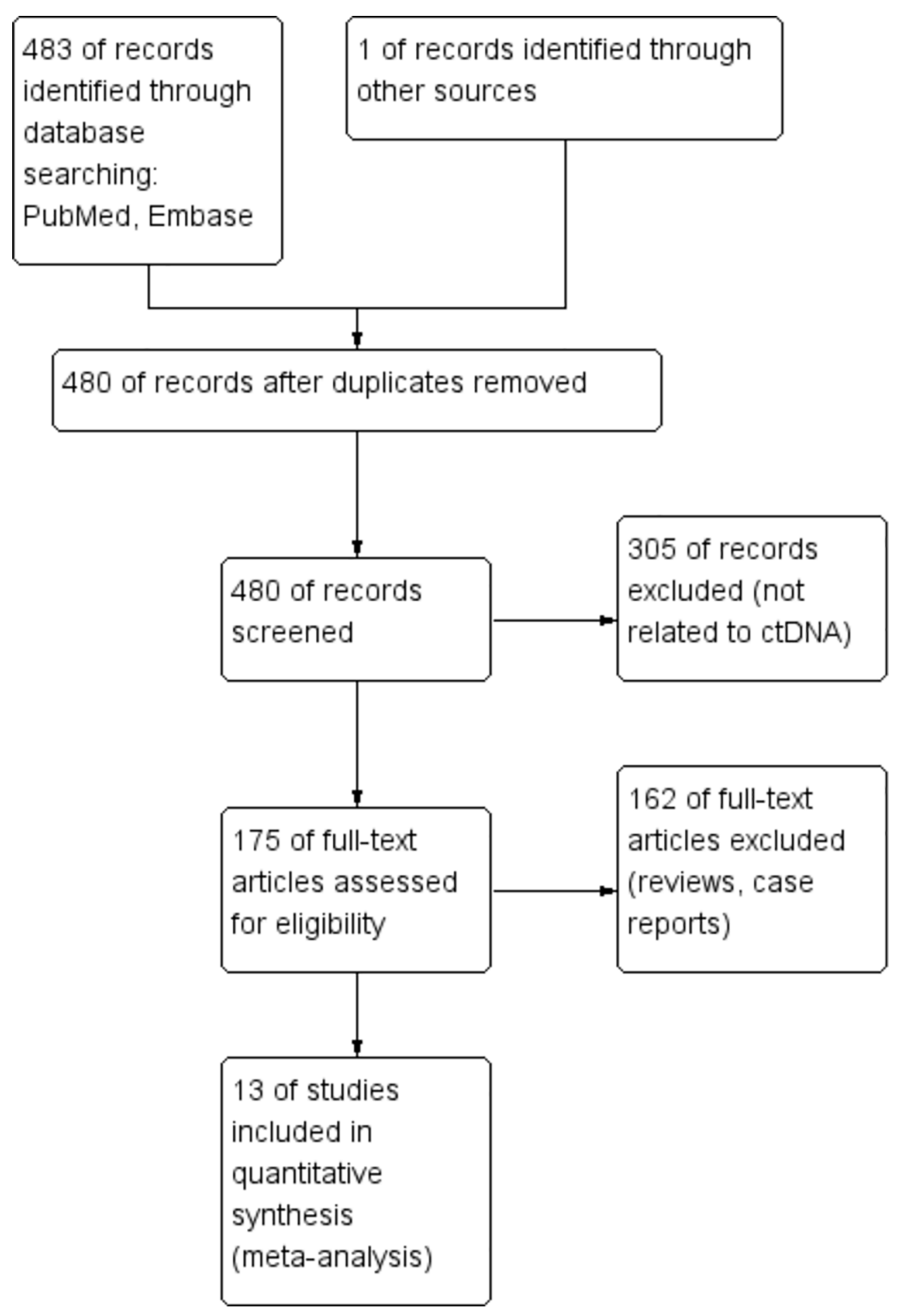

FIGURE 1 | Enrollment process of the included studies. The processes of identification, screening, eligibility, and inclusion are shown.

ctDNA levels were associated with shorter OS (HR $=3.35,95 \%$ $\mathrm{CI}=2.49-4.51, p<0.00001)$ (Figure 4A). A total of nine studies were eligible for inclusion in the meta-analysis regarding the prognostic value of ctDNA levels in the PFS of patients receiving
ICI therapy. A statistically significant poorer PFS was also observed in patients with higher ctDNA levels, with a pooled HR of $3.28(95 \% \mathrm{CI}=2.47-4.35, p<0.00001)$ (Figure $4 \mathbf{B})$. In the subgroup analysis of the different timings of biomarkers, high 
TABLE 1 | Characteristics of the included studies.

\begin{tabular}{|c|c|c|c|c|c|c|c|c|c|c|}
\hline Authors & Year & $\begin{array}{l}\text { Cancer } \\
\text { type }\end{array}$ & Study type & $\begin{array}{c}\text { Biomarker } \\
\text { type }\end{array}$ & $\begin{array}{l}\text { Timing of } \\
\text { biomarker }\end{array}$ & $\begin{array}{l}\text { Biomarker } \\
\text { detection } \\
\text { method }\end{array}$ & Cutoff point & $\mathrm{ICI}$ & $\begin{array}{l}\text { Outcome } \\
\text { of interest }\end{array}$ & Results \\
\hline Chen et al. & 2020 & $\begin{array}{l}\text { Colorectal } \\
\text { cancer }\end{array}$ & Prospective & bTMB & Pretreatment & NGS & $\geq 28$ vs. $<28$ vts/Mb & $\begin{array}{l}\text { Tremelimumab, } \\
\text { durvalumab }\end{array}$ & OS & $\begin{array}{l}\mathrm{HR}=0.34,90 \% \\
\mathrm{Cl}=0.18-0.63 \\
p=0.004\end{array}$ \\
\hline Lee et al. & 2020 & Melanoma & Prospective & ctDNA & Pretreatment & PCR & $\begin{array}{l}\text { Undetectable vs. } \\
\text { detectable }\end{array}$ & $\begin{array}{l}\text { Pembrolizumab, } \\
\text { nivolumab, } \\
\text { ipilimumab }\end{array}$ & OS & $\begin{array}{l}\mathrm{HR}=0.51,95 \% \\
\mathrm{Cl}=0.28-0.94 \\
p=0.03\end{array}$ \\
\hline Wang et al. & 2020 & NSCLC & Prospective & bTMB & $\begin{array}{l}\text { Not } \\
\text { mentioned }\end{array}$ & NGS & $\geq 6$ vs. $<6$ vts $/ \mathrm{Mb}$ & $\begin{array}{l}\text { Atezolizumab, } \\
\text { nivolumab, } \\
\text { pembrolizumab, } \\
\text { tislelizumab, } \\
\text { toripalimab }\end{array}$ & OS & $\begin{array}{l}\mathrm{HR}=0.92,95 \% \\
\mathrm{Cl}=0.46-1.82 \\
p=0.80\end{array}$ \\
\hline Wang et al. & 2020 & NSCLC & Prospective & $\begin{array}{l}\text { MSAF } \\
\text { (ctDNA) }\end{array}$ & $\begin{array}{l}\text { Not } \\
\text { mentioned }\end{array}$ & NGS & $\begin{array}{l}\text { Top } 25 \% \text { vs. } \\
\text { bottom } 75 \%\end{array}$ & $\begin{array}{l}\text { Atezolizumab, } \\
\text { nivolumab, } \\
\text { pembrolizumab, } \\
\text { tislelizumab, } \\
\text { toripalimab }\end{array}$ & OS & $\begin{array}{l}\mathrm{HR}=2.72,95 \% \\
\mathrm{Cl}=1.33-5.59 \\
p=0.005\end{array}$ \\
\hline Chen et al. & 2020 & $\begin{array}{l}\text { Biliary } \\
\text { tract } \\
\text { cancer }\end{array}$ & Prospective & ctDNA & Posttreatment & NGS & $\begin{array}{l}\text { Positive vs. } \\
\text { negative }\end{array}$ & Camrelizumab & $\begin{array}{l}\text { OS and } \\
\text { PFS }\end{array}$ & $\begin{array}{l}\text { OS: } \mathrm{HR}=1.77, \\
95 \% \mathrm{Cl}=0.78- \\
3.99, p=0.16 \\
\text { PFS: } \mathrm{HR}=2.83, \\
95 \% \mathrm{Cl}=1.27- \\
6.28, p=0.007\end{array}$ \\
\hline Chen et al & 2020 & $\begin{array}{l}\text { Biliary } \\
\text { tract } \\
\text { cancer }\end{array}$ & Prospective & bTMB & $\begin{array}{l}\text { Not } \\
\text { mentioned }\end{array}$ & NGS & $\begin{array}{l}\text { Top } 25 \% \text { vs. } \\
\text { bottom } 75 \%\end{array}$ & Camrelizumab & $\begin{array}{l}\text { OS and } \\
\text { PFS }\end{array}$ & $\begin{array}{l}\text { OS: } \mathrm{HR}=1.05 \\
95 \% \mathrm{Cl}=0.43- \\
2.54, p=0.92 \\
\text { PFS: } \mathrm{HR}=2.57 \\
95 \% \mathrm{Cl}=1.08- \\
6.12, p=0.03\end{array}$ \\
\hline $\begin{array}{l}\text { Pedersen } \\
\text { et al. }\end{array}$ & 2020 & Melanoma & Prospective & ctDNA & Posttreatment & PCR & $\begin{array}{l}\text { Detectable vs. } \\
\text { undetectable }\end{array}$ & $\begin{array}{l}\text { Pembrolizumab, } \\
\text { nivolumab, } \\
\text { ipilimumab }\end{array}$ & PFS & $\begin{array}{l}\mathrm{HR}=7.89,95 \% \\
\mathrm{Cl}=1.40-44.6 \\
p=0.019\end{array}$ \\
\hline $\begin{array}{l}\text { Marsavela } \\
\text { et al. }\end{array}$ & 2020 & Melanoma & Prospective & ctDNA & Pretreatment & PCR & $\begin{array}{l}\leq 20 \text { vs. }>20 \\
\text { copies } / \mathrm{ml}\end{array}$ & $\begin{array}{l}\text { Nivolumab, } \\
\text { pembrolizumab, } \\
\text { ipilimumab }\end{array}$ & PFS & $\begin{array}{l}\mathrm{HR}=0.42,95 \% \\
\mathrm{Cl}=0.22-0.83 \\
p=0.006\end{array}$ \\
\hline $\begin{array}{l}\text { Anagnostou } \\
\text { et al. }\end{array}$ & 2020 & NSCLC & Prospective & ctDNA & Clearance & NGS & $\begin{array}{l}\text { No complete } \\
\text { reduction vs. } \\
\text { complete reduction }\end{array}$ & Unclear & $\begin{array}{l}\text { OS and } \\
\text { PFS }\end{array}$ & $\begin{array}{l}\text { OS: } \mathrm{HR}=6.91 \\
95 \% \mathrm{Cl}=1.37- \\
34.97, p=0.02 \\
\text { PFS: } \mathrm{HR}=5.36, \\
95 \% \mathrm{Cl}=1.57- \\
18.35, p= \\
0.007\end{array}$ \\
\hline $\begin{array}{l}\text { Goldberg } \\
\text { et al. }\end{array}$ & 2018 & NSCLC & Prospective & ctDNA & Clearance & NGS & $\begin{array}{l}>50 \% \text { vs. } \leq 50 \% \\
\text { decrease in mutant } \\
\text { allele fraction from } \\
\text { baseline }\end{array}$ & Unclear & $\begin{array}{l}\text { OS and } \\
\text { PFS }\end{array}$ & $\begin{array}{l}\text { OS: } \mathrm{HR}=0.17 \\
95 \% \mathrm{Cl}=0.05- \\
0.62, p=0.007 \\
\text { PFS: HR=0.29, } \\
95 \% \mathrm{Cl}=0.09- \\
0.89, p=0.03\end{array}$ \\
\hline Cabel et al. & 2017 & $\begin{array}{l}\text { NSCLC, } \\
\text { etc. }\end{array}$ & Prospective & ctDNA & Posttreatment & NGS & $\begin{array}{l}\text { Detectable vs. } \\
\text { undetectable }\end{array}$ & $\begin{array}{l}\text { Nivolumab, } \\
\text { pembrolizumab }\end{array}$ & $\begin{array}{l}\text { OS and } \\
\text { PFS }\end{array}$ & $\begin{array}{l}\text { OS: } \mathrm{HR}=15, \\
95 \% \mathrm{Cl}=2.5- \\
94.9, p=0.004 \\
\text { PFS: } \mathrm{HR}=10.2, \\
95 \% \mathrm{Cl}=2.5- \\
41, p<0.001\end{array}$ \\
\hline $\begin{array}{l}\text { Herbreteau } \\
\text { et al. }\end{array}$ & 2021 & Melanoma & Prospective & ctDNA & Clearance & PCR & $\begin{array}{l}\text { Increase vs. } \\
\text { decrease }\end{array}$ & $\begin{array}{l}\text { Nivolumab/ } \\
\text { nivolumab + } \\
\text { ipilimumab }\end{array}$ & $\begin{array}{l}\text { OS and } \\
\text { PFS }\end{array}$ & $\begin{array}{l}\text { OS: } \mathrm{HR}=7.49, \\
95 \% \mathrm{Cl}=2.59- \\
24.10, p= \\
0.0002 \\
\text { PFS: } \mathrm{HR}= \\
12.74,95 \% \mathrm{Cl}= \\
3.81-53.25, p< \\
0.0001\end{array}$ \\
\hline
\end{tabular}

(Continued) 
TABLE 1 | Continued

\begin{tabular}{|c|c|c|c|c|c|c|c|c|c|c|}
\hline Authors & Year & $\begin{array}{l}\text { Cancer } \\
\text { type }\end{array}$ & Study type & $\begin{array}{c}\text { Biomarker } \\
\text { type }\end{array}$ & $\begin{array}{l}\text { Timing of } \\
\text { biomarker }\end{array}$ & $\begin{array}{c}\text { Biomarker } \\
\text { detection } \\
\text { method }\end{array}$ & Cutoff point & $\mathrm{ICl}$ & $\begin{array}{l}\text { Outcome } \\
\text { of interest }\end{array}$ & Results \\
\hline Ricciuti et al. & 2021 & NSCLC & Retrospective & ctDNA & Clearance & NGS & $\begin{array}{l}\text { Decrease vs. } \\
\text { increase }\end{array}$ & Pembrolizumab & $\begin{array}{l}\text { OS and } \\
\text { PFS }\end{array}$ & $\begin{array}{l}\text { OS: } \mathrm{HR}=0.34, \\
95 \% \mathrm{Cl}=0.15- \\
0.75, p=0.008 \\
\text { PFS: } \mathrm{HR}=0.29, \\
95 \% \mathrm{Cl}=0.14- \\
0.60, p= \\
0.0007\end{array}$ \\
\hline Zhang et al. & 2020 & $\begin{array}{l}\text { Advanced } \\
\text { cancers }\end{array}$ & Prospective & ctDNA & Posttreatment & $\begin{array}{l}\text { Not } \\
\text { mentioned }\end{array}$ & $\begin{array}{l}\text { Below median vs. } \\
\text { above median }\end{array}$ & $\begin{array}{l}\text { Durvalumab } \pm \\
\text { tremelimumab }\end{array}$ & $\begin{array}{l}\text { OS and } \\
\text { PFS }\end{array}$ & $\begin{array}{l}\mathrm{HR}=0.13,95 \% \\
\mathrm{Cl}=0.05-0.34 \\
\mathrm{HR}=0.41,95 \% \\
\mathrm{Cl}=0.25-0.68\end{array}$ \\
\hline Powles et al. & 2021 & $\begin{array}{l}\text { Urothelial } \\
\text { carcinoma }\end{array}$ & Prospective & ctDNA & Clearance & PCR & Clear vs. not clear & Atezolizumab & OS & $\begin{array}{l}\mathrm{HR}=0.14,95 \% \\
\mathrm{Cl}=0.03-0.59\end{array}$ \\
\hline
\end{tabular}

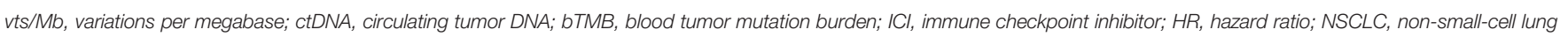
cancer; MSAF, maximum somatic allele frequency; NGS, next-generation sequencing; PCR, polymerase chain reaction; OS, overall survival; PFS, progression-free survival.

posttreatment ctDNA levels significantly correlated with shorter OS in cancer patients receiving ICIs $(\mathrm{HR}=5.09,95 \% \mathrm{CI}=1.43-$ $18.07, p=0.01)$. In addition, patients without ctDNA clearance had worse OS $(\mathrm{HR}=4.94,95 \% \mathrm{CI}=2.96-8.26, p<0.00001)$. There was only one study on the relationship between the pretreatment ctDNA levels and OS, and the results showed that high pretreatment ctDNA levels were correlated with worse overall survival $(\mathrm{HR}=1.95,95 \% \mathrm{CI}=1.06-3.57, p=$ 0.03) (Figure 5). As for PFS, patients with high posttreatment ctDNA levels had shorter PFS ( $\mathrm{HR}=3.00,95 \% \mathrm{CI}=2.02-4.46$, $p<0.00001)$. Similarly, patients with ctDNA clearance had longer PFS $(\mathrm{HR}=4.61,95 \% \mathrm{CI}=2.78-7.65, p<0.00001)$. In addition, high levels of pretreatment ctDNA were significantly correlated with shorter PFS $(\mathrm{HR}=2.34,95 \% \mathrm{CI}=1.20-4.55, p=$ 0.01) (Figure 6).

\section{Relationship Between bTMB and Response to Immunotherapy}

There was only one study with PFS as an outcome indicator. Estimation of the prognostic value of bTMB in the PFS of patients receiving ICI therapy revealed that a high bTMB was significantly associated with shorter PFS $(\mathrm{HR}=2.57,95 \% \mathrm{CI}=$ $1.08-6.12, p=0.03)$. There were a total of three studies on the prognostic value of bTMB in the OS of cancer patients receiving immunotherapy. The pooled results showed that there was no statistically significant difference in the OS benefits between a higher and a lower bTMB $(\mathrm{HR}=0.68,95 \% \mathrm{CI}=0.33-1.37, p=$ 0.28) (Figure 7).

\section{Heterogeneity}

In the analysis of the prognostic effect of ctDNA in patients receiving immunotherapy, no significant heterogeneity was observed in the outcomes of PFS and OS $\left(I^{2}=30 \%, p<\right.$ $\left.0.00001 ; I^{2}=45 \%, p<0.00001\right)$; thus, both were analyzed with the fixed effects models. The heterogeneity between the studies on bTMB was greater than $50 \%\left(I^{2}=60 \%\right)$, so the random effects model was selected.

\section{DISCUSSION}

The efficacy of ICIs mainly depends on the tumor burden and the immune system of the host (10-12). At present, the main tools used to evaluate disease burden and the host immune status are radiologic assessments (CT and MRI) and tTMB (13-17), but they all have their own limitations. The clinical decision to continue or suspend ICI therapy is usually guided by continuous radiographic observations of changes in the tumor. However, CT and MRI are unable to identify patients who can achieve benefits early because tumors usually shrink slowly (18). In addition, radiographs often fail to identify whether transient tumor enlargements come from true disease progression or pseudoprogression, the latter referring to immune cell infiltration (18-20). Relevant evidence has shown that the existence of ctDNA occurs earlier than the recurrence of radiographic imaging, and it dynamically changes with the patient's response to treatment (21). As a prognostic factor of the host immune status, tTMB is also not completely satisfactory. Firstly, the measurement of tTMB requires tumor biopsy material, which may cause trauma and bleeding. Secondly, not all cancer patients meet the criteria for tissue biopsy (22). Thirdly, tTMB can only reflect the mutation burden of local tumor tissues and does not focus on the whole body (23). Finally, tTMB is unable to dynamically monitor tumor burden in real time. In order to more accurately identify patients who are most likely to benefit from immunotherapy, new biomarkers are needed to compensate for the lack of the evaluation tools mentioned above. ctDNA and bTMB are expected to become new biomarkers, but their exact prognostic roles in ICI therapy remain to be clarified. To the best of our knowledge, this is the first systematic review and metaanalysis on the prognostic impact of ctDNA and bTMB in patients undergoing immunotherapy.

Some studies claimed that a higher bTMB indicated better prognosis, which means longer PFS and OS in patients receiving immunotherapy $(24,25)$, while others hold the opposite opinion (26). The pooled results of our meta-analysis revealed that higher ctDNA levels resulted in shorter PFS $(\mathrm{HR}=3.28,95 \% \mathrm{CI}=2.47-$ 

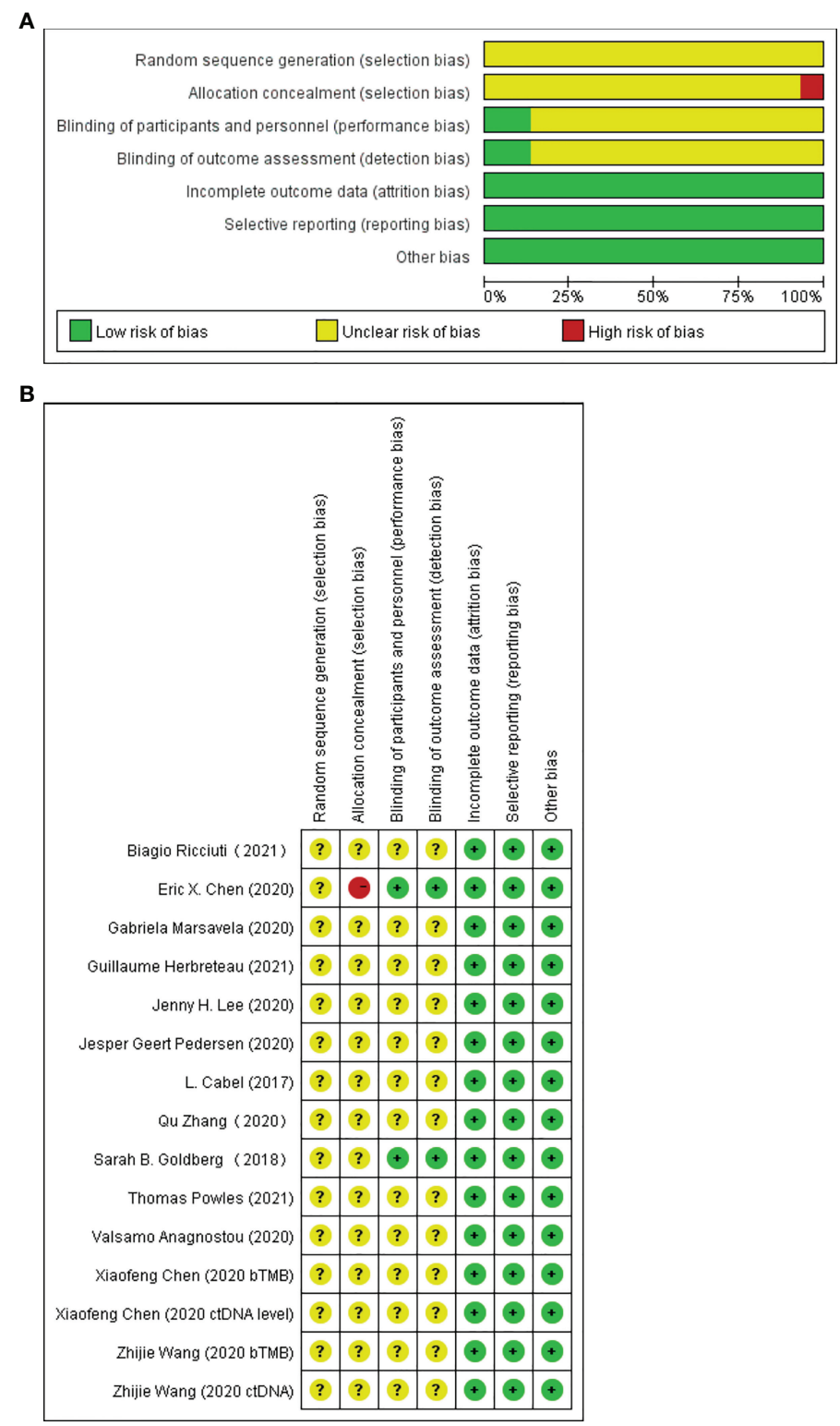

FIGURE 2 | Assessment of risk of bias at the study level. (A) Risk of bias graph: review authors' judgments of each risk of bias item presented as percentages across all included full report studies. (B) Risk of bias summary: review authors' judgments of each risk of bias item.

$4.35, p<0.00001)$ and $\mathrm{OS}(\mathrm{HR}=3.35,95 \% \mathrm{CI}=2.49-4.51, p<$ $0.00001)$. In the subgroup analysis of biomarkers at different time points, patients with high levels of pretreatment or posttreatment ctDNA and patients without ctDNA clearance during treatment all had worse prognosis (PFS and OS) in immunotherapy. Regarding $\mathrm{bTMB}$, no statistically significant difference was observed between a high and a low bTMB in OS prognosis $(\mathrm{HR}=0.68,95 \% \mathrm{CI}=0.33-1.37, p=0.28)$.

ctDNA is a single- or double-stranded DNA released into the blood by tumor cells. The proportion of ctDNA in cfDNA ranges widely, and it is determined by the synthesis of tumor location, phenotype, and differentiation degree (27). Therefore, ctDNA can reflect the burden of tumors and carry the original tumor mutations (28). Theoretically, a higher ctDNA level reveals a greater tumor burden, resulting in a poorer prognosis. Zhao et al. (29) also observed that, in liver cancer, higher ctDNA levels were more associated with larger tumor volumes than was alphafetoprotein (AFP). This finding was consistent with the results of our meta-analysis.

Synonymous variation, non-synonymous variation, and variation of unknown significance (VUS) are the three methods used to calculate bTMB (3). New somatic mutations in tumor cells result in new antigen expression, and the production of tumor-specific antigens is an important 


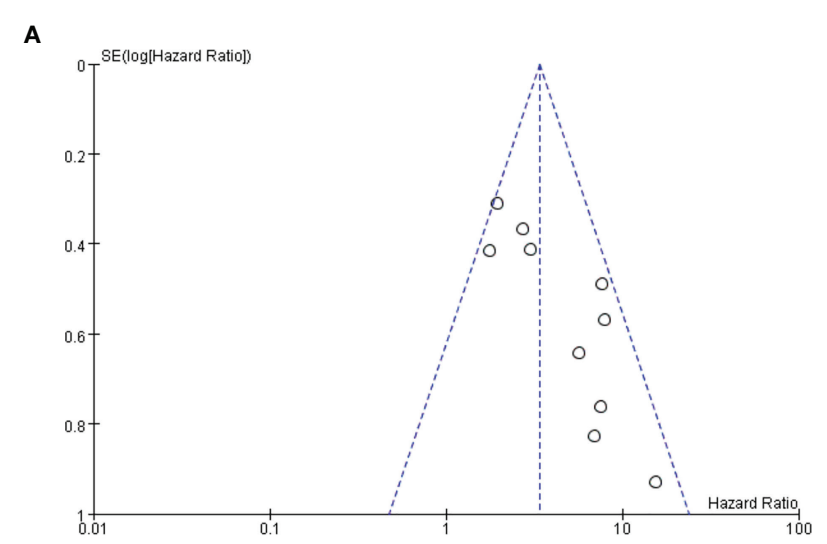

B

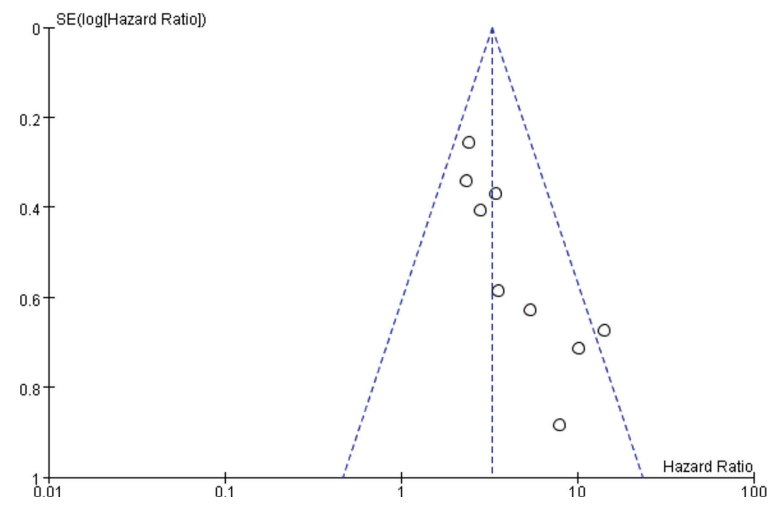

FIGURE 3 | (A, B) Funnel plots. Funnel plot analysis on potential publication bias for overall survival (OS) (A) and progression-free survival (PFS) (B).

prerequisite for $\mathrm{T}$ cells to recognize tumors $(30,31)$. Moreover, neoantigens produced by mutations in tumor somatic cells have been confirmed to activate the immune response of T cells (32). Previous studies have demonstrated that a higher tTMB is associated with longer OS and PFS in patients receiving immunotherapy (33-35). The feasibility and accuracy of bTMB measured from blood samples based on ctDNA and the positive association between $\mathrm{BTMB}$ and TMB in tumor tissues have been confirmed $(36,37)$. Therefore, in theory, bTMB also has prognostic value in patients receiving ICIs, and a higher bTMB corresponds to better survival. However, the pooled results of our meta-analysis revealed no statistically significant relationship between a higher $\mathrm{DTMB}$ and better OS. Why bTMB cannot be a prognostic factor in patients receiving ICIs will be explained in the following. The detection method for bTMB inevitably leads to the following results: ctDNA levels have an important impact on the abundance of bTMB. In this way, a higher bTMB may be accompanied by higher ctDNA levels, and the latter is closely correlated with worse prognosis. As a consequence, a higher bTMB does not necessarily reveal longer OS and PFS; likewise, a lower bTMB is not necessarily related to shorter OS and PFS. In conclusion, some problems remain to be overcome before the clinical implementation of bTMB. To effectively determine the prognostic value of $\mathrm{bTMB}$ in cancer patients undergoing immunotherapy, the integration of bTMB and other blood biomarkers in the future may be required.

Our meta-analysis explored the prognostic value of high or low ctDNA and bTMB in patients receiving immunotherapy, but did not address the predictive effect of ctDNA or bTMB on the outcome of immunotherapy. The results of the trial, published in Nature by Powles et al., revealed that the ctDNA-positive patients in the atezolizumab group had better prognosis than those in the observation group, suggesting that ctDNA may be a predictor of the efficacy of ICIs. This conclusion is helpful in the clinical decision-making of clinicians. For patients with positive ctDNA after tumor surgery, the use of ICIs may be an option to improve survival. However, there are limited studies on the predictive indicators of the efficacy of immunotherapy, and this conclusion needs to be confirmed by more data in future studies.

Our study had certain limitations. Firstly, since the detection technology of ctDNA and bTMB in blood is still in the initial stages of development, there will be more or less inconsistencies between the measured values and the true values, which is also the main reason for the different cutoff points of ctDNA and bTMB in all the studies included in our meta-analysis. Therefore, the stability of our meta-analysis results was affected. Secondly, the number of studies included in the meta-analysis was relatively small, especially the number of studies on bTMB. Thirdly, in addition to the different cutoff points of the biomarkers that affect the results of the analysis, there are other factors that will cause heterogeneity in the meta-analysis results and affect the authenticity and reliability of the final results. Although we have performed a subgroup analysis on the prognostic value of ctDNA in patients receiving immunotherapy at different time points, the details of each study in each subgroup were diverse. For example, although they were all studies on the prognostic value of posttreatment ctDNA levels in patients receiving ICIs, some studies focused on ctDNA at 6-8 weeks after immunotherapy while others explored ctDNA at 8-10 weeks after immunotherapy. In addition, for studies on the prognostic impact of ctDNA clearance, the definition and the standard of ctDNA clearance were different. Finally, the detection methods for ctDNA and bTMB used by the studies included in our meta-analysis were not uniform (PCR and NGS, respectively), which would also impact the results of the analysis. This requires the continuous updating and improvement of the detection methods for these two biomarkers in the future.

\section{CONCLUSION}

In the past, ctDNA and bTMB have received increased attention in the field of targeted therapy and chemo/radiotherapy (38-41), but there has been no consensus regarding their prognostic role in patients receiving ICIs. Our meta-analysis results demonstrated that the levels and the clearance of ctDNA can be used as independent prognostic factors for immunotherapy, while the prognostic impact of bTMB in cancer patients undergoing immunotherapy is worth further discussion and exploration.

Monitoring the ctDNA levels for ICI therapy has the following advantages: it can be performed in real time, is noninvasive, and is 
A

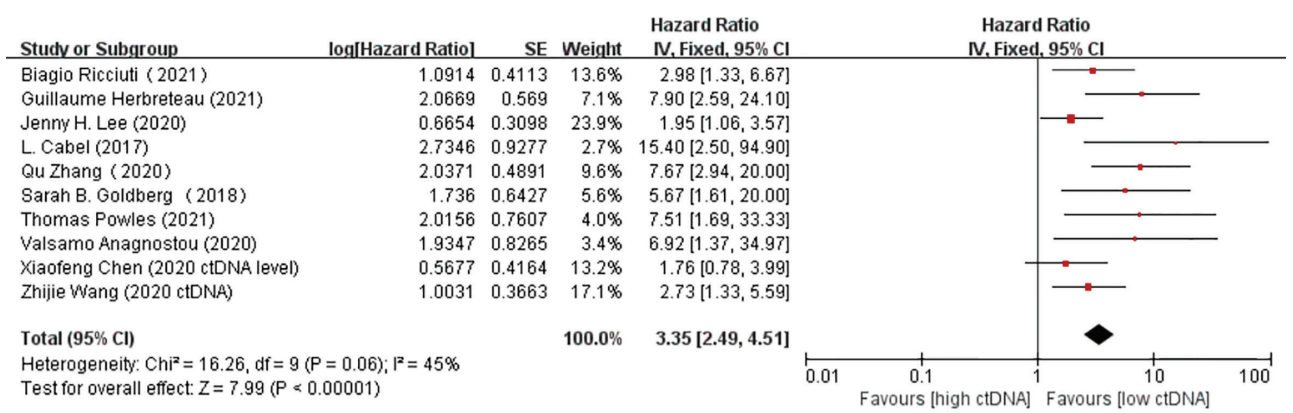

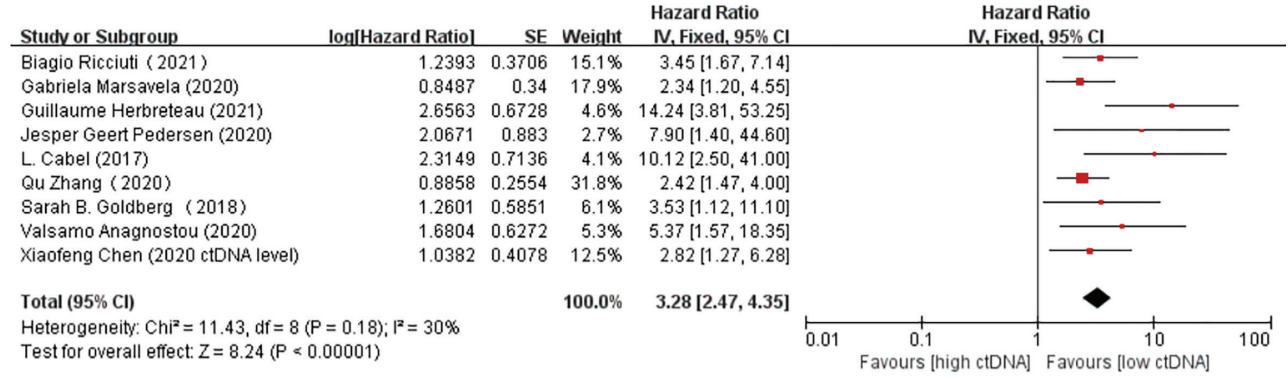

FIGURE 4 | (A, B) Forest plots of the fixed effects meta-analysis on the efficacy of circulating tumor DNA (ctDNA) for overall survival (OS) (A) and for progressionfree survival (PFS) (B).

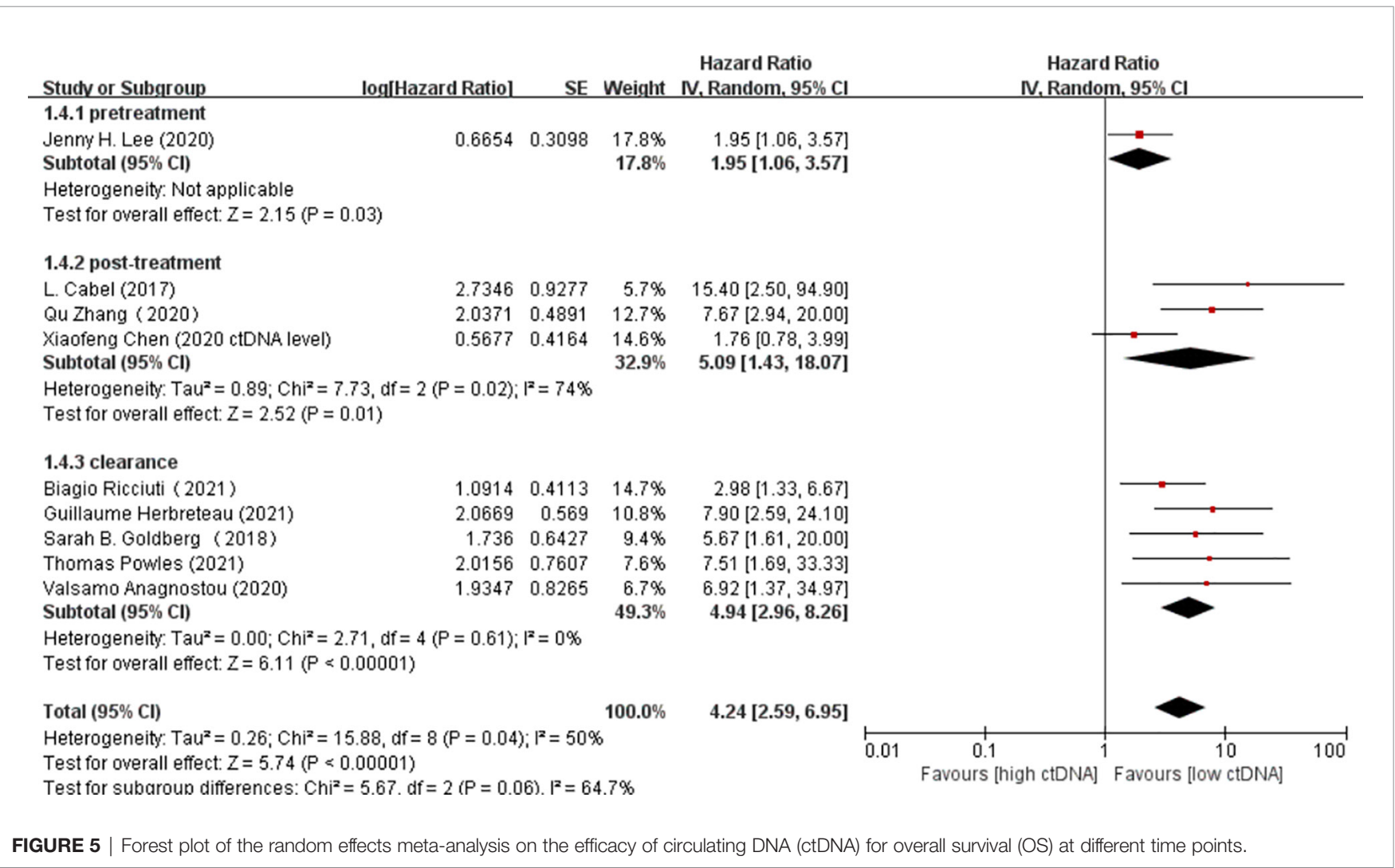




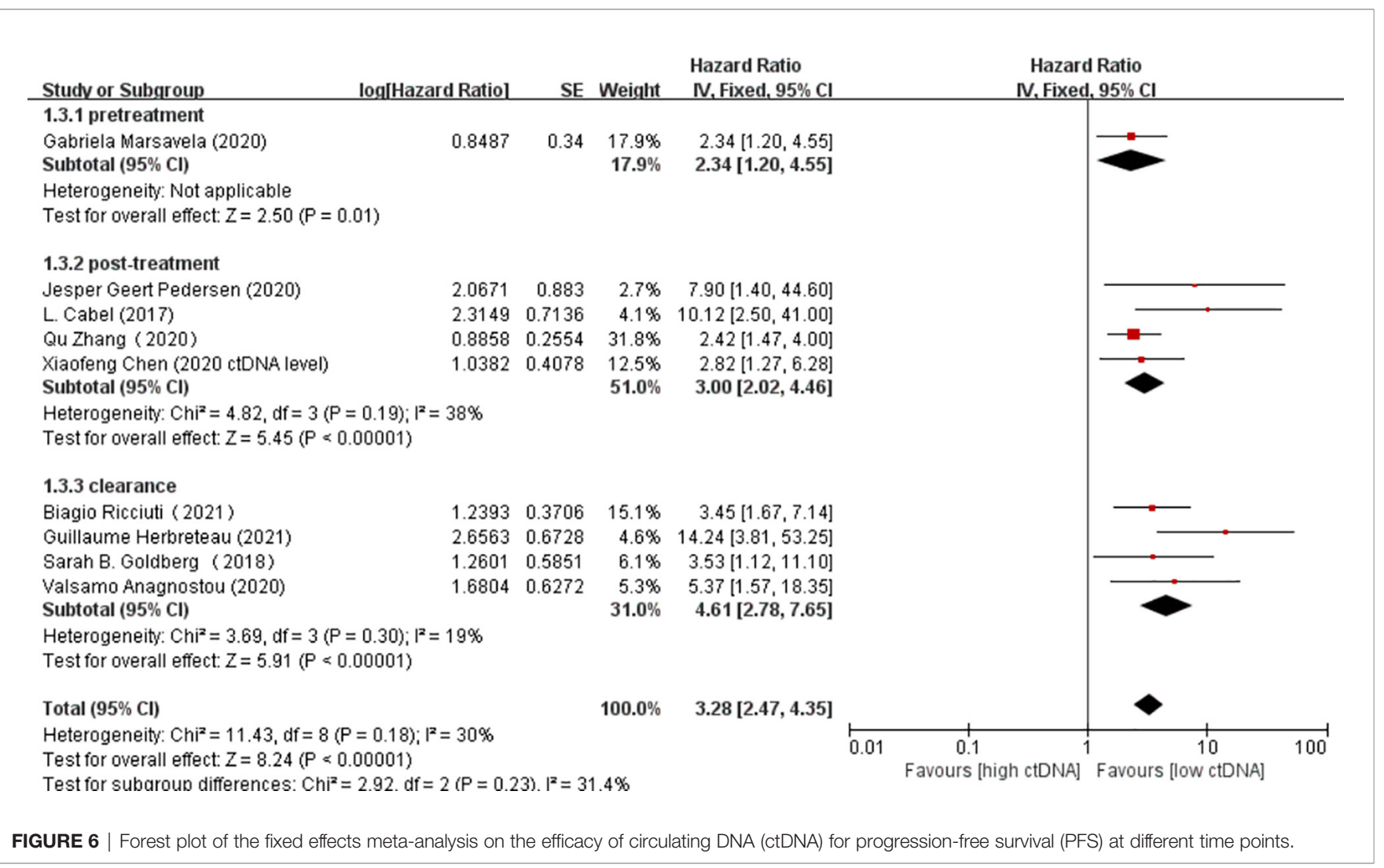

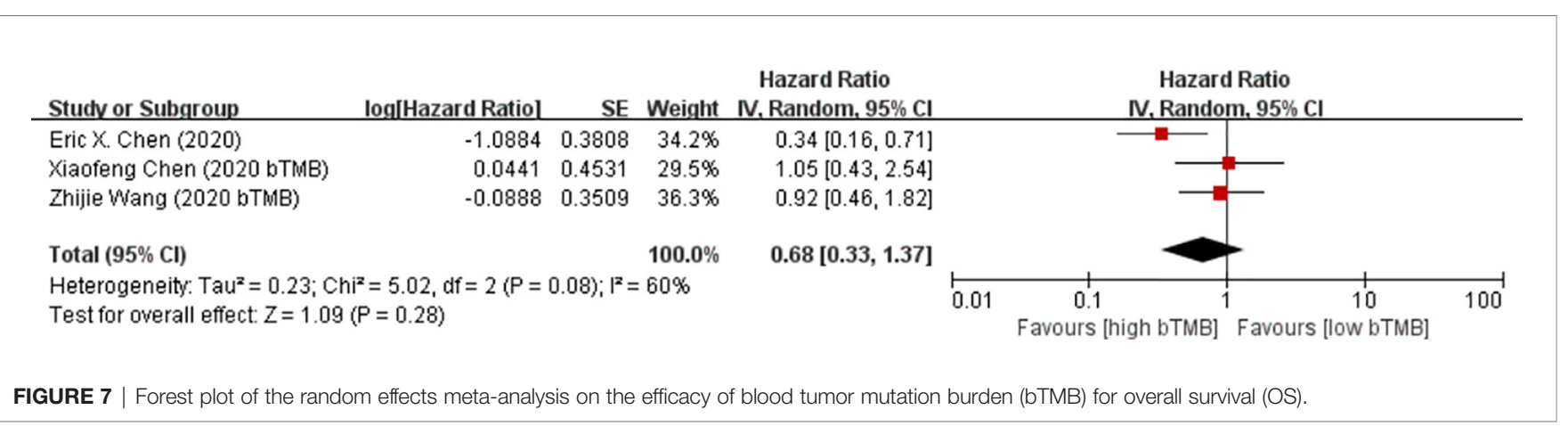

ultrasensitive. Therefore, it can be a good prognostic factor for immunotherapy in patients with cancer. Monitoring ctDNA can be used as an important supplement to conventional imaging and help in making timely therapeutic management decisions. Due to the limitations of the current detection technology and standards, bTMB cannot be directly used as a prognostic factor to effectively predict the survival of patients undergoing treatment with ICIs.

\section{AUTHOR CONTRIBUTIONS}

YW, NL, and MP conceptualized the study. PR, YJ, and ZX contributed to the methodology. JW helped with software. RL did the formal analysis. JW, JF, PW, and XC prepared the original draft. YW reviewed and edited the manuscript. All authors contributed to the article and approved the submitted version.

\section{FUNDING}

This work was supported by grants from the National Natural Science Foundation of China (81770169), National Natural Science Foundation of China (81802980) and National Natural Science Foundation of China (81102024). 


\section{REFERENCES}

1. Cabel L, Proudhon C, Romano E, Girard N, Lantz O, Stern MH, et al. Clinical Potential of Circulating Tumour DNA in Patients Receiving Anticancer Immunotherapy. Nat Rev Clin Oncol (2018) 15(10):639-50. doi: 10.1038/ s41571-018-0074-3

2. Boonstra PA, Wind TT, van Kruchten M, Schuuring E, Hospers G, van der Wekken AJ, et al. Clinical Utility of Circulating Tumor DNA as a Response and Follow-Up Marker in Cancer Therapy. Cancer Metastasis Rev (2020) 39 (3):999-1013. doi: 10.1007/s10555-020-09876-9

3. Chae YK, Davis AA, Agte S, Pan A, Simon NI, Iams WT, et al. Clinical Implications of Circulating Tumor DNA Tumor Mutational Burden (ctDNA TMB) in Non-Small Cell Lung Cancer. Oncologist (2019) 24(6):820-8. doi: 10.1634/theoncologist.2018-0433

4. McNamara MG, Jacobs T, Lamarca A, Hubner RA, Valle JW, Amir E. Impact of High Tumor Mutational Burden in Solid Tumors and Challenges for Biomarker Application. Cancer Treat Rev (2020) 89:102084. doi: 10.1016/ j.ctrv.2020.102084

5. Motzer RJ, Escudier B, George S, Hammers HJ, Srinivas S, Tykodi SS, et al. Nivolumab Versus Everolimus in Patients With Advanced Renal Cell Carcinoma: Updated Results With Long-Term Follow-Up of the Randomized, Open-Label, Phase 3 CheckMate 025 Trial. Cancer-Am Cancer Soc (2020) 126(18):4156-67. doi: 10.1002/cncr.33033

6. Liu L, Bai X, Wang J, Tang XR, Wu DH, Du SS, et al. Combination of TMB and CNA Stratifies Prognostic and Predictive Responses to Immunotherapy Across Metastatic Cancer. Clin Cancer Res (2019) 25(24):7413-23. doi: 10.1158/1078-0432.CCR-19-0558

7. Anagnostou V, Forde PM, White JR, Niknafs N, Hruban C, Naidoo J, et al. Dynamics of Tumor and Immune Responses During Immune Checkpoint Blockade in Non-Small Cell Lung Cancer. Cancer Res (2019) 79(6):1214-25. doi: 10.1158/0008-5472.CAN-18-1127

8. Lee JH, Menzies AM, Carlino MS, McEvoy AC, Sandhu S, Weppler AM, et al. Longitudinal Monitoring of ctDNA in Patients With Melanoma and Brain Metastases Treated With Immune Checkpoint Inhibitors. Clin Cancer Res (2020) 26(15):4064-71. doi: 10.1158/1078-0432.CCR-19-3926

9. Marsavela G, Lee J, Calapre L, Wong SQ, Pereira MR, McEvoy AC, et al. Circulating Tumor DNA Predicts Outcome From First-, But Not Second-Line Treatment and Identifies Melanoma Patients Who May Benefit From Combination Immunotherapy. Clin Cancer Res (2020) 26(22):5926-33. doi: 10.1158/1078-0432.CCR-20-2251

10. Sakata Y, Kawamura K, Ichikado K, Shingu N, Yasuda Y, Eguchi Y, et al. The Association Between Tumor Burden and Severe Immune-Related Adverse Events in Non-Small Cell Lung Cancer Patients Responding to ImmuneCheckpoint Inhibitor Treatment. Lung Cancer (2019) 130:159-61. doi: 10.1016/j.lungcan.2019.02.011

11. Seban RD, Mezquita L, Berenbaum A, Dercle L, Botticella A, Le Pechoux C, et al. Baseline Metabolic Tumor Burden on FDG PET/CT Scans Predicts Outcome in Advanced NSCLC Patients Treated With Immune Checkpoint Inhibitors. Eur J Nucl Med Mol Imaging (2020) 47(5):1147-57. doi: 10.1007/ s00259-019-04615-x

12. Picard E, Verschoor CP, Ma GW, Pawelec G. Relationships Between Immune Landscapes, Genetic Subtypes and Responses to Immunotherapy in Colorectal Cancer. Front Immunol (2020) 11:369. doi: 10.3389/ fimmu.2020.00369

13. Muhlberg A, Holch JW, Heinemann V, Huber T, Moltz J, Maurus S, et al. The Relevance of CT-Based Geometric and Radiomics Analysis of Whole Liver Tumor Burden to Predict Survival of Patients With Metastatic Colorectal Cancer. Eur Radiol (2021) 31(2):834-46. doi: 10.1007/s00330-020-07192-y

14. Sun G, Cheng C, Li X, Wang T, Yang J, Li D. Metabolic Tumor Burden on Postsurgical PET/CT Predicts Survival of Patients With Gastric Cancer. Cancer Imaging (2019) 19(1):18. doi: 10.1186/s40644-019-0205-9

15. Iv M, Liu X, Lavezo J, Gentles AJ, Ghanem R, Lummus S, et al. Perfusion MRIBased Fractional Tumor Burden Differentiates Between Tumor and Treatment Effect in Recurrent Glioblastomas and Informs Clinical Decision-Making. AJNR Am J Neuroradiol (2019) 40(10):1649-57. doi: 10.3174/ajnr.A6211

16. Nan Z, Guoqing W, Xiaoxu Y, Yin M, Xin H, Xue L, et al. The Predictive Efficacy of Tumor Mutation Burden (TMB) on Nonsmall Cell Lung Cancer
Treated by Immune Checkpoint Inhibitors: A Systematic Review and MetaAnalysis. BioMed Res Int (2021) 2021:1780860. doi: 10.1155/2021/1780860

17. Sholl LM, Hirsch FR, Hwang D, Botling J, Lopez-Rios F, Bubendorf L, et al. The Promises and Challenges of Tumor Mutation Burden as an Immunotherapy Biomarker: A Perspective From the International Association for the Study of Lung Cancer Pathology Committee. J Thorac Oncol (2020) 15(9):1409-24. doi: 10.1016/j.jtho.2020.05.019

18. Goldberg SB, Narayan A, Kole AJ, Decker RH, Teysir J, Carriero NJ, et al. Early Assessment of Lung Cancer Immunotherapy Response via Circulating Tumor DNA. Clin Cancer Res (2018) 24(8):1872-80. doi: 10.1158/1078-0432.CCR-17-1341

19. Markovic SN, Galli F, Suman VJ, Nevala WK, Paulsen AM, Hung JC, et al. Non-Invasive Visualization of Tumor Infiltrating Lymphocytes in Patients With Metastatic Melanoma Undergoing Immune Checkpoint Inhibitor Therapy: A Pilot Study. Oncotarget (2018) 9(54):30268-78. doi: 10.18632/ oncotarget.25666

20. Cabel L, Riva F, Servois V, Livartowski A, Daniel C, Rampanou A, et al. Circulating Tumor DNA Changes for Early Monitoring of Anti-PD1 Immunotherapy: A Proof-of-Concept Study. Ann Oncol (2017) 28(8):19962001. doi: $10.1093 /$ annonc/mdx212

21. Powles T, Assaf ZJ, Davarpanah N, Banchereau R, Szabados BE, Yuen KC et al. ctDNA Guiding Adjuvant Immunotherapy in Urothelial Carcinoma. Nature (2021) 595(7867):432-7. doi: 10.1038/s41586-021-03642-9

22. Allgauer M, Budczies J, Christopoulos P, Endris V, Lier A, Rempel E, et al. Implementing Tumor Mutational Burden (TMB) Analysis in Routine Diagnostics-a Primer for Molecular Pathologists and Clinicians. Transl Lung Cancer Res (2018) 7(6):703-15. doi: 10.21037/tlcr.2018.08.14

23. Friedlaender A, Nouspikel T, Christinat Y, Ho L, McKee T, Addeo A. TissuePlasma TMB Comparison and Plasma TMB Monitoring in Patients With Metastatic Non-Small Cell Lung Cancer Receiving Immune Checkpoint Inhibitors. Front Oncol (2020) 10:142. doi: 10.3389/fonc.2020.00142

24. Chen EX, Jonker DJ, Loree JM, Kennecke HF, Berry SR, Couture F, et al. Effect of Combined Immune Checkpoint Inhibition vs Best Supportive Care Alone in Patients With Advanced Colorectal Cancer: The Canadian Cancer Trials Group CO.26 Study. JAMA Oncol (2020) 6(6):831-8. doi: 10.1001/ jamaoncol.2020.0910

25. Killock D. bTMB is a Promising Predictive Biomarker. Nat Rev Clin Oncol (2019) 16(7):403. doi: 10.1038/s41571-019-0202-8

26. Wang Z, Duan J, Wang G, Zhao J, Xu J, Han J, et al. Allele FrequencyAdjusted Blood-Based Tumor Mutational Burden as a Predictor of Overall Survival for Patients With NSCLC Treated With PD-(L)1 Inhibitors. J Thorac Oncol (2020) 15(4):556-67. doi: 10.1016/j.jtho.2019.12.001

27. Pessoa LS, Heringer M, Ferrer VP. ctDNA as a Cancer Biomarker: A Broad Overview. Crit Rev Oncol Hematol (2020) 155:103109. doi: 10.1016/ j.critrevonc.2020.103109

28. Cheng F, Su L, Qian C. Circulating Tumor DNA: A Promising Biomarker in the Liquid Biopsy of Cancer. Oncotarget (2016) 7(30):48832-41. doi: 10.18632/oncotarget.9453

29. Zhao W, Qiu L, Liu H, Xu Y, Zhan M, Zhang W, et al. Circulating Tumor DNA as a Potential Prognostic and Predictive Biomarker During Interventional Therapy of Unresectable Primary Liver Cancer. J Gastrointest Oncol (2020) 11(5):1065-77. doi: 10.21037/jgo-20-409

30. Lee M, Samstein RM, Valero C, Chan TA, Morris L. Tumor Mutational Burden as a Predictive Biomarker for Checkpoint Inhibitor Immunotherapy. Hum Vaccin Immunother (2020) 16(1):112-5. doi: 10.1080/21645515.2019.1631136

31. Subudhi SK, Vence L, Zhao H, Blando J, Yadav SS, Xiong Q, et al. Neoantigen Responses, Immune Correlates, and Favorable Outcomes After Ipilimumab Treatment of Patients With Prostate Cancer. Sci Transl Med (2020) 12(537). doi: $10.1126 /$ scitranslmed.aaz3577

32. Jardim DL, Goodman A, de Melo GD, Kurzrock R. The Challenges of Tumor Mutational Burden as an Immunotherapy Biomarker. Cancer Cell (2021) 39 (2):154-73. doi: 10.1016/j.ccell.2020.10.001

33. Samstein RM, Lee CH, Shoushtari AN, Hellmann MD, Shen R, Janjigian YY, et al. Tumor Mutational Load Predicts Survival After Immunotherapy Across Multiple Cancer Types. Nat Genet (2019) 51(2):202-6. doi: 10.1038/s41588-018-0312-8

34. Alborelli I, Leonards K, Rothschild SI, Leuenberger LP, Savic PS, Mertz KD, et al. Tumor Mutational Burden Assessed by Targeted NGS Predicts Clinical Benefit From Immune Checkpoint Inhibitors in Non-Small Cell Lung Cancer. J Pathol (2020) 250(1):19-29. doi: 10.1002/path.5344 
35. Greally M, Chou JF, Chatila WK, Margolis M, Capanu M, Hechtman JF, et al. Clinical and Molecular Predictors of Response to Immune Checkpoint Inhibitors in Patients With Advanced Esophagogastric Cancer. Clin Cancer Res (2019) 25(20):6160-9. doi: 10.1158/1078-0432.CCR-18-3603

36. Si H, Kuziora M, Quinn KJ, Helman E, Ye J, Liu F, et al. A Blood-Based Assay for Assessment of Tumor Mutational Burden in First-Line Metastatic NSCLC Treatment: Results From the MYSTIC Study. Clin Cancer Res (2021) 27 (6):1631-40. doi: 10.1158/1078-0432.CCR-20-3771

37. Zhang X, Zhao W, Wei W, You Z, Ou X, Sun M, et al. Parallel Analyses of Somatic Mutations in Plasma Circulating Tumor DNA (ctDNA) and Matched Tumor Tissues in Early-Stage Breast Cancer. Clin Cancer Res (2019) 25 (21):6546-53. doi: 10.1158/1078-0432.CCR-18-4055

38. Zhu C, Zhuang W, Chen L, Yang W, Ou WB. Frontiers of ctDNA, Targeted Therapies, and Immunotherapy in Non-Small-Cell Lung Cancer. Transl Lung Cancer Res (2020) 9(1):111-38. doi: 10.21037/tlcr.2020.01.09

39. Ji D, Zhang D, Zhan T, Jia J, Han W, Li Z, et al. Tumor Mutation Burden in Blood Predicts Benefit From Neoadjuvant Chemo/Radiotherapy in Locally Advanced Rectal Cancer. Genomics (2021) 113(1 Pt 2):957-66. doi: 10.1016/j.ygeno.2020.10.029

40. Nie W, Qian J, Xu MD, Gu K, Qian FF, Lu J, et al. Prognostic and Predictive Value of Blood Tumor Mutational Burden in Patients With Lung Cancer Treated With Docetaxel. J Natl Compr Canc Netw (2020) 18(5):582-9. doi: $10.6004 /$ jnccn.2019.7383
41. Ma F, Guan Y, Yi Z, Chang L, Li Q, Chen S, et al. Assessing Tumor Heterogeneity Using ctDNA to Predict and Monitor Therapeutic Response in Metastatic Breast Cancer. Int J Cancer (2020) 146(5):1359-68. doi: 10.1002/ ijc.32536

Conflict of Interest: The authors declare that the research was conducted in the absence of any commercial or financial relationships that could be construed as a potential conflict of interest.

Publisher's Note: All claims expressed in this article are solely those of the authors and do not necessarily represent those of their affiliated organizations, or those of the publisher, the editors and the reviewers. Any product that may be evaluated in this article, or claim that may be made by its manufacturer, is not guaranteed or endorsed by the publisher.

Copyright (c) 2021 Wei, Feng, Weng, Xu, Jin, Wang, Cui, Ruan, Luo, Li and Peng. This is an open-access article distributed under the terms of the Creative Commons Attribution License (CC BY). The use, distribution or reproduction in other forums is permitted, provided the original author(s) and the copyright owner(s) are credited and that the original publication in this journal is cited, in accordance with accepted academic practice. No use, distribution or reproduction is permitted which does not comply with these terms. 